\section{Clinical variables related to small bowel obstruction: comparison of patients with and without Crohn's disease}

\author{
Awad Al Qahtani, ${ }^{1}$ Christina Holcroft, ${ }^{2}$ \\ Philip H. Gordon, ${ }^{1}$ Andrew Szilagyi ${ }^{3}$ \\ ${ }^{1}$ Division of Colorectal Surgery, \\ ${ }^{2}$ Department of Epidemiology, ${ }^{3}$ Division \\ of Gastroenterology, Jewish General \\ Hospital, McGill University, \\ School of Medicine Montreal, Canada
}

\section{Abstract}

Small bowel obstruction is a known complication of Crohn's disease. Determining need for operation is a demanding task. The aim of this study was to fine tune the decision-making process by evaluating standard clinical and laboratory parameters in small bowel obstruction of any cause and compare etiologies. Consecutive patients with Crohn's disease and small bowel obstruction were selected retrospectively and compared to a randomly selected group of non Crohn's patients with obstruction over a 9 year period. Twenty-two clinical, laboratory and radiological variables were assessed for the following outcomes: i) diagnosis of Crohn's; ii) operative or non operative treatment in Crohn's; iii) operative or non operative treatment without Crohn's; iv) exacerbation or adhesions causing obstruction among Crohn's patients. Multivariable models were developed for each outcome using logistic regression. Age less than 50, history of smoking, Jewish ethnicity, white count $>11 \times 10^{9}$, neutrophils $>7.5 \times 10^{9}$ and platelet volume $<9.9 \mathrm{fL}$, supported the diagnosis of Crohn's disease. Operation in Crohn's disease within the same admission was associated with a history of smoking, temperature $>38^{\circ}$, high pulse $>100$, leukocytosis $\left(>11 \times 10^{9}\right)$ and obstruction on abdominal scan, while operation in patients without Crohn's in the sentinel admission, was associated with temperature $>38^{\circ}$, tachycardia, leukocytosis $\left(>11 \times 10^{9}\right)$ and previous operation. Confirmation of these predictive patterns in a validation group could help in clinical decisions regarding therapeutic options in an emergency setting.

\section{Introduction}

Small bowel obstruction (SBO) is one of the leading causes of emergency surgical admissions to hospital. The predominant cause of SBO has changed from hernias to adhesions in the last 2-3 decades. ${ }^{1}$ This latter etiology accounts for about $74 \%$ of cases and has a tendency to recur more often after hospitalization. $^{2}$

In cases of SB0 of any cause, the course of action to take, operative or non operative, requires substantial experience. Attempts to accurately predict the best course have been the subject of frequent reports and reviews. ${ }^{3-6}$ Strangulation of small bowel is a dreaded outcome of missed surgical opportunity. General laboratory features have not been previously helpful, 7,8 but modern methods of coaxial tomography have provided greater sensitivity and specificity in this decision making. ${ }^{6,9,10}$

Crohn's disease (CD) is found to be the second most common cause of SBO, albeit at a markedly lower frequency (7\%), and it is also associated with recurrent bouts of SBO. ${ }^{1}$ However, the cause may be acute or chronic, stricturing due to ongoing activity, or may be due to adhesions, especially in patients who have undergone previous operation.

Unfortunately, traditional markers of disease severity (e.g. CD activity index or Harvey Bradshaw index), nor do markers of inflammatory activity, allow distinction to be made as to the cause of obstruction. ${ }^{11,12}$ In active inflammation medical therapy often relieves partial or even complete SBO without operative intervention. ${ }^{13}$ However, in the course of this disease (until quite recently), most patients have required at least one operation. ${ }^{14}$ In the late twentieth century, operative rates for CD were $70 \%$ within 20 years of diagnosis. ${ }^{14}$

However, comparisons of operative rates, more recently from Europe and North America, suggest that overall these have been falling. ${ }^{15}$ Small bowel obstruction represents the most common indication for operation in patients with small bowel or ileocolonic Crohn's disease. ${ }^{14,15}$ We evaluated patients' charts who presented to the emergency department with features of suspected SBO. We compared possible prognostic factors for distinguishing SBO with or without CD, associations with operative versus non operative requirements, and preoperative indicators favoring CD or adhesions in patients having previously undergone operation for CD.

\section{Materials and Methods}

We conducted a retrospective chart review of all patients presenting to the emergency department of the Jewish General hospital (JGH) with suspected SBO and diagnosed Crohn's disease between January 1, 2000 to December 31, 2008 (this period encompassed the initiation of the hospital data base in 2000 to the beginning of the study undertaking in
Correspondence: Andrew Szilagyi, Division of Gastroenterology, Jewish General Hospital, 3755 Cote St. Catherine Road, Montreal, Quebec H3T 1E2, Canada. Tel. +1.514.340.8144.

E-mail: aszilagy@jgh.mcgill.ca

Key words: clinical predictors, small bowel obstruction.

Conflict of interests: the authors report no potential conflict of interests.

Contributions: AQ, AS, study conception and design, acquisition, analysis and interpretation of data, drafting of manuscript, critical revision; PG, CH, study conception and design, analysis and interpretation of data, drafting of manuscript; critical revision.

Received for publication: 18 August 2011.

Revision received: 10 April 2012.

Accepted for publication: 13 April 2012.

This work is licensed under a Creative Commons Attribution NonCommercial 3.0 License (CC BYNC 3.0).

(C) Copyright A. Al Qahtani et al., 2012

Licensee PAGEPress, Italy

Gastroenterology Insights 2012; 4:e4

doi:10.4081/gi.2012.e4

early 2009). An additional group of patients with suspected $\mathrm{SBO}$ without a diagnosis of $\mathrm{CD}$ selected at the discretion of the medical archives were also reviewed from the same period for a sample comparison. A total of 260 charts were reviewed (Figure 1). This study was approved both by the JGH ethics committee as well as the Medical Archives and no patients were contacted.

Suspected SBO diagnosis was based on any combination of appropriate history of abdominal pain of short or acute duration (days or hours) associated with or without nausea and/or vomiting. Radiological evaluation suggesting SBO was carried out in all included patients. Crohn's disease was based on any combination of history, appropriate radiology, previous endoscopy with or without histology. ${ }^{16}$ Twenty-two clinical, radiological and laboratory variables were extracted from the charts. Except for data pertaining to previous medical history, radiological and laboratory variables were selected from the time of hospitalization for the suspected SBO. Both radiological and laboratory (blood test) variables were deemed to be relevant for the peri-emergency visit. Clinical variables examined were age, sex, ethnicity, smoking history (smoking vs. never), ethanol intake, and previous abdominal pelvic operation. In the case of CD duration (greater or less than 10 years) and whether medical therapy was currently or pre- 
viously administered was also recorded. Physical findings of fever (temperature $\geq 38^{\circ} \mathrm{C}$ ), pulse (rate $\geq 100$ beats/minute), abdominal tenderness and whether a mass could be palpated were recorded. Radiological tests included abdominal $\mathrm{X}$ rays and co-axial tomography (CT) of abdomen and pelvis were recorded. Results of either test were recorded as positive or negative for SB0 without assessing details of results. All CTs during the period used multislice techniques. Laboratory variables included: hemoglobin (Hbg, g/L, normal 120-175 for men and women), mean corpuscular volume (MCV, fL, normal 80-96), platelet count (Plat, $\times 10^{9}$, normal $150-400$ ), mean platelet volume (MPV, fL, 9.9-11.8), total white blood cell count (WBC, $\times 10^{9}$, normal 4-11), neutrophil count (PMNL, $\times 10^{9}, 1.8-7.5$ ), lymphocyte count (Lymph, $\times 10^{9}$, normal 1.2-3.5) and albumin (g/L, normal 35-51).

\section{Statistical analysis}

A data base was established and analysis was conducted using Intercooled Stata 8.2 statistical software (StataCorp, College Station, TX, USA). Standard laboratory cutoff values were used to generate dichotomous predictors for laboratory measurements representing above or below normal limits. Two-way associations between categorical variables were examined using a chi-square test or a Fisher's exact test (if any table cell count was less than 5). Four primary outcomes were evaluated: i) CD vs no $\mathrm{CD}$; ii) operative $v s$ non-operative treatment among CD patients; 3 ) operative $v s$ non-operative treatment among patients without CD; and iv) cause in CD: exacerbation vs adhesions. Separate logistic regression models were used to characterize the binary outcomes. Specifically, computer generated models were applied that predicted outcome within the current CD and non-CD populations using clinical, radiological and laboratory variables. Logistic regression was used to estimate odds ratios, and models were reported for the $\log$ odds, which is a linear function of predictors and has the following form: constant + coefficient_1*(value of predictor_1) + coefficient_2*(value of predictor_2) + etc. To interpret this logistic regression model, a summed value would be calculated for each patient, according to his/her specific patient characteristics. When a patient's summed value is greater than 0 this indicates that the patient is more likely to have the specified outcome.

Multivariable models were considered so that several predictors could be evaluated at one time.In multivariable models for outcomes 2 and 3 , some predictors unique to either treatment were identified which means that either all patients in one category of the unique predictor had operation or all patients in one predictor category had non-operative treatment. These predictors could not be included in final multivariable models because the estimate for the odds ratio would be plus or minus infinity and so were described separately.

\section{Results}

A total of 260 patient charts were reviewed. Excluded and included patients are outlined in Figure 1. Table 1 lists demographics of the groups; SBO with CD and SBO without CD. In addition to other diagnostic parameters, $83.7 \%$ of SBO with CD, patients had a colonoscopy at some time and had histological support for their inflammatory bowel disease (IBD). Within the group, SB0 with CD, 81 patients underwent surgery, 10 of these for contained perforations, and 66 were treated medically. Within the SB0 without CD group, 31 and 27 patients underwent surgery or conservative therapy respectively. None of these patients had acute perforations. The 4 primary outcomes as outlined above are reported in Tables 2, 3, 4 and are described below. For the first objective, to determine clinical and laboratory

Table 1. Demographic features of patients presenting with a small bowel obstruction with or without Crohn's disease.

\begin{tabular}{ccc} 
SBO with CD (n.147) & $\begin{array}{c}\text { SBO without CD (n.58) } \\
\text { Average (range) }\end{array}$ & $\begin{array}{c}\text { Average (range) } \\
\text { Age, years }\end{array}$ \\
\hline Count (column \%) & Count (column \%)
\end{tabular}

\begin{tabular}{lcc} 
Age $<50$ years* & $106(72 \%)$ & $13(22 \%)$ \\
Gender & $76(52 \%)$ & $29(50 \%)$ \\
$\quad$ Male & $71(48 \%)$ & $29(50 \%)$ \\
Female & & \\
\hline Ethnicity* & $70(48 \%)$ & $16(28 \%)$ \\
$\quad$ Jewish & $23(16 \%)$ & $0(0 \%)$ \\
French Canadian & $47(32 \%)$ & $37(64 \%)$ \\
Other & $7(5 \%)$ & $5(9 \%)$ \\
$\quad$ Missing & $99(68 \%)$ & $8(14 \%)$ \\
History of smoking* & $146(99 \%)$ & $49(84 \%)$ \\
\hline No regular ethanol intake* & $78(53 \%)$ & $\mathrm{N} / \mathrm{A}$ \\
Duration CD $>10$ years & $76(52 \%)$ & $41(71 \%)$ \\
\hline Prior CD med therapy & $58(39 \%)$ & $24(41 \%)$ \\
Previous operation* & $64(44 \%)$ & $54(93 \%)^{* *}$ \\
\hline Fever (temperature $\left.\geq 38^{\circ} \mathrm{C}\right)$ & $116(79 \%)$ & $56(97 \%)$ \\
Obstruction on abdominal X-rays & $100(68 \%)^{* *}$ & $0(0 \%)$ \\
\hline Obstruction on abdominal/pelvic CT scan & $10(7 \%)$ & \\
Localized perforations &
\end{tabular}

SBO, small bowel obstruction; CD, Crohn's disease; CT, computed tomography. *Statistically different $\mathrm{P}<0.001$; **there were statistically significant differences between patients treated operatively and non-operatively. In the non CD group, $100 \%$ of patients treated operatively had obstruction on an abdominal $\mathrm{X}$-ray compared with $85 \%$ treated non-operatively $(\mathrm{P}=0.041)$. In the $\mathrm{CD}$ group, $90 \%$ of those treated operatively had obstruction on a CT scan compared with 41\% treated non-operatively $(\mathrm{P}<0.001)$.

Table 2. Variables used to derive a multivariable computer generated model of small bowel obstruction (SBO) and presence of Crohn's disease (CD) compared with SBO and no CD.

\begin{tabular}{lccc} 
Variable & $\begin{array}{c}\text { SBO with CD (n.147) } \\
\text { Count (column \%) }\end{array}$ & $\begin{array}{c}\text { SBO without CD (n.58) } \\
\text { Count (column \%) }\end{array}$ & P \\
Age less than 50 & $106(72 \%)$ & $13(22 \%)$ & $<0.001$ \\
History of smoking & $99(68 \%)$ & $8(14 \%)$ & $<0.001$ \\
\hline Jewish ethnicity & $70(50 \%)$ & $16(30 \%)$ & 0.013 \\
WBC $>11 \times 10 \mathrm{E} 9$ & $46(32 \%)$ & $34(59 \%)$ & $<0.001$ \\
\hline PMNL $>7.5 \times 10^{9}$ & $63(43 \%)$ & $5(9 \%)$ & $<0.001$ \\
Lymph no. $<1.2 \times 10^{9}$ & $71(48 \%)$ & $14(24 \%)$ & 0.002 \\
\hline Platelets $>400 \times 10^{9}$ & $32(22 \%)$ & $4(7 \%)$ & 0.013 \\
MPV $<9.9 \mathrm{fL}$ & $128(87 \%)$ & $27(47 \%)$ & $<0.001$ \\
\hline
\end{tabular}

SBO, small bowel obstruction; CD, Crohn's disease; WBC,white blood count; PMNL, polymorphonuclear lymphocytes; MPV, mean platelet volume; fL, fluid liters. 
variables characteristic of $\mathrm{CD}$, we censored information about previous history of $\mathrm{CD}$ and radiological imaging. Table 2 lists those characteristics which were more commonly found in CD compared to non-CD patients with SBO, when considering diagnostic variables separately. In multivariable analysis described in Table 4, six of the variables listed were retained (all with $P$ values $<0.003$ ). The $\log$ odds of having $\mathrm{CD}$ is described by the following formula (of linear function of predictors): [2.1 (if age $<50)+2.0$ (if Jewish ethnicity) +2.6 (if history of smoking) - 3.6 (if WBC >11) +3.8 (if PMNL count $>7.5)+1.9$ (if MPV <9.9) -2.5 (constant)] (refer to Table 4 for confidence intervals). If a patient's summed value is greater than 0 , this indicates that the patient is more likely to have the specified outcome (in this case, CD). In our sample of patients the model correctly classified $92 \%$ overall. This value represents the percent that are correctly classified as SBO with CD plus the percent that are correctly classified as SBO without CD.

The next objective was to determine variables that might help solidify clinical judgment of whether to operate or not. The results are reported for patients with SBO and CD and then SBO without CD (outcomes 2 and 3). Variables individually associated with either clinical judgment in SBO with CD and also in SBO without CD are listed in Table 3. In SBO with CD (outcome 2), all 54 patients with tachycardia ( $>100)$ (37\% of total) required operation and none received non-operative treatment. Because such a predictor cannot be included in a regression model (estimate of odds would be infinity), a multivariable analysis was conducted including all patients and ignoring pulse rate. The model for the log odds of requiring an operation among patients with
CD and SBO follows the formula in Table 4: [3.2 (if history of smoking) +3.1 (if positive obstruction on CT scan, that is an identified focal point of obstruction) +3.6 (if fever $>38^{\circ}$ C) -5.5 (constant)]. If the summed value is $>0$ for a particular patient, then operative intervention is more likely and $91 \%$ of the sample group were correctly classified in either therapeutic option with this model. This value again represents the sum \% of patients classified as operative or non-operative.The prediction does not change when tachycardia, is taken into consideration. For SB0 without CD (objective 3), all patients with tachycardia
$(>100)$ and fever $\left(>38^{\circ} \mathrm{C}\right)$ received operation, while patients without any previous operation and without obstruction on abdominal plain films received non-operative management. Ninety-three percent (54/58) of patients could be classified as either having operative or nonoperative treatment based on these 4 variables, with 27 patients correctly classified as having operative and 27 patients correctly classified as having non-operative treatment. [PMNL was also technically a strong predictor, with all 5 patients with high PMNL having nonoperative treatment. Since this was a counterintuitive finding, PMNL was not included in

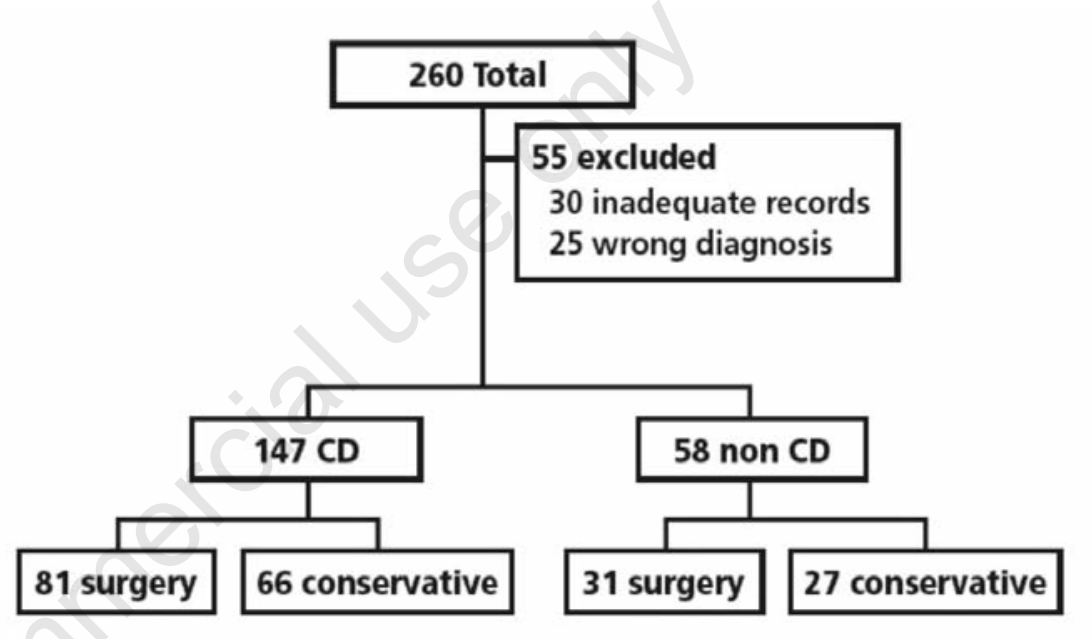

Figure 1. Outline of charts reviewed between January 1, 2000 and December 31, 2008. Included and excluded patients are shown.

Table 3. Variables used to derive multivariable models of small bowel obstruction operation in patients with and without Crohn's disease.

\begin{tabular}{|c|c|c|c|c|c|c|}
\hline Variable & $\begin{array}{l}\text { Operative Rx } \\
\text { (n.81) } \\
\text { Count } \\
\text { (column \%) }\end{array}$ & $\begin{array}{c}\text { SBO with CD } \\
\text { Nonoperative Rx } \\
\text { (n.66) } \\
\text { Count } \\
\text { (column \%) }\end{array}$ & $\mathbf{P}$ & $\begin{array}{l}\text { Operative Rx } \\
\text { (n.31) } \\
\text { Count } \\
\text { (column \%) }\end{array}$ & $\begin{array}{l}\text { SBO without CD } \\
\text { Nonoperative Rx } \\
(\mathrm{n} .27) \\
\text { Count } \\
\text { (column \%) }\end{array}$ & $\mathbf{P}$ \\
\hline Previous medical treatment of CD & $57(70 \%)$ & $19(29 \%)$ & $<0.001$ & $\mathrm{~N} / \mathrm{A}$ & $\mathrm{N} / \mathrm{A}$ & $\mathrm{N} / \mathrm{A}$ \\
\hline Duration $C D>10$ years & $49(63 \%)$ & $29(46 \%)$ & 0.046 & $\mathrm{~N} / \mathrm{A}$ & $\mathrm{N} / \mathrm{A}$ & $\mathrm{N} / \mathrm{A}$ \\
\hline History of smoking & $78(96 \%)$ & $21(32 \%)$ & $<0.001$ & $3(10 \%)$ & $5(19 \%)$ & 0.453 \\
\hline No previous operation & $49(60 \%)$ & $40(61 \%)$ & 0.989 & $0(0 \%)$ & $17(63 \%)$ & $<0.001^{*}$ \\
\hline No obstruction on abdominal X-ray & $20(25 \%)$ & $11(17 \%)$ & 0.236 & $0(0 \%)$ & $4(15 \%)$ & $0.041^{*}$ \\
\hline Obstruction on CT abdomen / pelvis & $73(90 \%)$ & $27(41 \%)$ & $<0.001$ & $31(100 \%)$ & $25(93 \%)$ & 0.212 \\
\hline Temperature $\geq 38^{\circ} \mathrm{C}$ & $59(73 \%)$ & $5(8 \%)$ & $<0.001$ & $24(77 \%)$ & $0(0 \%)$ & $<0.001^{*}$ \\
\hline Pulse rate $\geq 100$ beats/min & $54(67 \%)$ & $0(0 \%)$ & $<0.001^{*}$ & $12(39 \%)$ & $0(0 \%)$ & $<0.001^{*}$ \\
\hline $\mathrm{WBC}>11 \times 10^{9}$ & $37(46 \%)$ & $9(14 \%)$ & $<0.001$ & $29(94 \%)$ & $5(19 \%)$ & $<0.001$ \\
\hline PMNL $>7.5 \times 10^{9}$ & $43(53 \%)$ & $20(30 \%)$ & 0.005 & $0(0 \%)$ & $5(19 \%)$ & $0.016^{*}$ \\
\hline $\mathrm{MCV}<80 \mathrm{fL}$ & $22(27 \%)$ & $10(15 \%)$ & 0.079 & $13(42 \%)$ & $3(11 \%)$ & 0.017 \\
\hline
\end{tabular}

*Strongly divisive predictors of either operative or non-operative treatment; explanation in results. SBO, small bowel obstruction; CD, Crohn's disease; WBC, white blood count; PMNL, polymorphonuclear lymphocytes; MPV, mean platelet volume; fL, fluid liters. 
the overall model]. A multivariable model was run on the remaining significant variables and only leukocytosis remained significant. The log odds estimate for requiring an operation in this model was: [4.16 (if WBC >11) -2.4 (constant)] (Table 4). Again, a value greater than 0 means that operation is more likely and $88 \%$ of patients were correctly classified as to correct treatment. When classification took into consideration high WBC along with the unique sided predictors (high pulse, fever, lack of previous operation and lack of obstruction on abdominal x-ray), $98 \%$ of the group of patients with SBO and without CD were correctly classified as operative or non-operative. For the final objective we were interested to evaluate whether there were any preoperative variables in patients with SBO and CD which could predict intraoperative findings in such patients (outcome 4: CD exacerbation vs. adhesions). Only 2 variables proved to have predictive value. Jewish ethnicity in patients with CD favored finding $\mathrm{CD}$ at laparotomy (71\% CD exacerbation among Jewish vs. 48\% among others, $\mathrm{P}=0.035$ ) and a previous history of operation favored finding adhesions in these patients (97\% adhesions among the previous operative group vs. $4 \%$ among others, $\mathrm{P}<0.001)$. Neither abdominal $\mathrm{X}$ ray nor abdominal/pelvic CT predicted intraoperative findings although it is emphasized that radiological tests were used only dichotomously without attention to details.

\section{Discussion}

This study set out to evaluate specific adjunctive markers that would help to identify those patients with SBO who would require an operation within the same hospitalization in an emergency room setting. Also whether the causative factor was external adhesions or exacerbations (leading to acute inflammatory and edematous occlusion or chronic stricturing) in patients with CD. We were interested in evaluating whether clinical judgment resulting in the decision to operate or not could be translated quantitatively based on simple measurements in the emergency setting. Most studies evaluating markers in Crohn's disease evaluate a wide array demographic, genetic, clinical or laboratory variables, either to predict natural history, requirement for surgery, ${ }^{17-22}$ or need for surgery following the first resection. ${ }^{23-26}$ After a search on Pubmed and Google Scholar we did not find any paper dealing with an array of variables which could be used to aid in decision making about course of therapy to follow in the emergency setting of SBO in Crohn's disease. We did find a number of articles which deal with the value of ultrasound, ${ }^{4}$ CT scans, ${ }^{27}$ magnetic resonance imaging (MRI) ${ }^{28}$ or positron emission tomography scan, ${ }^{29}$ in precisely diagnosing obstruction and cause in Crohn's disease. In particular these radiological modalities do aid in distinguishing the presence of inflammation and may help in deciding medical versus surgical intervention in the immediate clinical circumstances. In case of intestinal obstruction without Crohn's disease similarly a number of variables may help decision to operate, ${ }^{5-7,12}$ but these were not very helpful. The role of CT has also been defined and could aid in decision to operate or not. ${ }^{11,30}$ Multiple predictors for need to operate in non CD related SBO was published by Ziellinski et $a l^{31}$ In this analysis, intraperitoneal fluid, mesenteric edema, lack of a small bowel feces sign and vomiting had a $96 \%$ sensitivity and $90 \%$ positive predictive value for need for surgery. However, in the case of CD, acute ischemia with free perforation is uncommon. In fact, only 10 patients in our sample (10\%) had a localized perforation. The markers of Ziellinski et al. would less likely apply to patients with CD. In the current study we initially evaluated clinical laboratory patterns which may be characteristic of CD. There were two considerations for this analysis. First, patients without prior history of Crohn's disease may present for the first time to the emergency (e.g. patients presenting with abdominal pain and/or suspected cases of acute appendix). A characteristic pattern may be present and raise suspicion of CD. Secondly, individual features are known to be associated with more severe disease. For example, the Montreal Classification lists ileal

Table 4. Results from logistic regression analysis for 3 models. Equations for estimates of the log odds are reported, which has the following structure: constant + coefficient_1*(value of predictor_1) + coefficient_2*(value of predictor_2) + etc. '--.' represents a variable that was not significant in a particular model. In each category of outcome: i) diagnosis of presence of Crohn's disease (CD), ii) operative or nonoperative therapy in small bowel obstruction (SBO) with $\mathrm{CD}$ or iii) same paradigm of therapy in SBO without CD, an outcome result of the respective formula of more than 0 , supports the listed first options (ie. diagnosis of CD in 1, operations in 2 and 3 ). Using each of the respective models, a correct outcome was obtained in 92\% (1 CD or not CD), 91\% (operate or not in SBO with CD) and 98\% (operate or not in SBO without $\mathrm{CD}$ ) in the generating population of patients.

\begin{tabular}{|c|c|c|c|}
\hline Variable & $\begin{array}{l}\text { Diagnosis CD no CD } \\
\text { CD vs. no CD } \\
(\mathrm{n}=191) \\
\text { Coefficient }(95 \% \mathrm{CI})\end{array}$ & $\begin{array}{c}\text { SBO with CD } \\
\text { Operation vs. Nonoperative } \mathrm{Rx} \\
(\mathrm{n}=146) \\
\text { Coefficient }(95 \% \mathrm{CI})\end{array}$ & $\begin{array}{c}\text { SBO without CD } \\
\text { Operative vs. Nonoperative Rx } \\
(\mathrm{n}=58) \\
\text { Coefficient }(95 \% \mathrm{CI})\end{array}$ \\
\hline Constant & $-2.54(-3.95,-1.12)$ & $-5.51(-7.55,-3.46)$ & $-2.40(-3.85,-0.95)$ \\
\hline Age less than 50 & $2.14(1.03,3.25)$ & --- & --- \\
\hline History of smoking & $2.55(1.29,3.80)$ & $3.24(1.74,4.73)$ & --- \\
\hline Jewish ethnicity & $2.02(0.70,3.34)$ & --- & --- \\
\hline Obstruction on CT abdomen/pelvis & Not included & $3.14(1.52,4.77)$ & Strong predictor \\
\hline Temperature $\geq 38^{\circ} \mathrm{C}$ & Not included & $3.64(1.93,5.35)$ & Strong predictor \\
\hline $\mathrm{WBC}>11 \times 10^{9}$ & $-3.56(-5.24,-1.89)$ & --- & $4.16(2.42,5.89)$ \\
\hline PMNL $>7.5 \times 10^{9}$ & $3.84(1.94,5.74)$ & --- & Strong predictor \\
\hline $\mathrm{MPV}<9.9 \mathrm{fL}$ & $1.87(0.66,3.08)$ & --- & --- \\
\hline Pulse rate $\geq 100$ beats/min & Not included & Strong predictor & Strong predictor \\
\hline No previous operation & Not included & --- & Strong predictor \\
\hline
\end{tabular}

P-values for all included variables in the models were $\leq 0.003$. For details about uniquely distributed predictors, see text and Table 3. SBO, small bowel obstruction; CD, Crohn's disease; WBC, white blood count; PMNL, polymorphonuclear lymphocytes; MPV, mean platelet volume; fL,fluid liters. 
or ileocolonic site in younger patients as variables for more aggressive disease. ${ }^{32}$ Similarly, smoking is thought to impact both on pathogenesis and on increased risk of relapse. ${ }^{33-35}$ Laboratory features of elevated platelets and a low MPV have also been described in active IBD. ${ }^{36}$ Importantly we did not evaluate C-reactive protein or sedimentation rate because these variables are infrequently measured in the emergency setting. Similarly, we did not evaluate effects of individual medications on therapeutic options, because subgroups of these would constitute insufficient population sizes for statistical purposes. While, history of any medical therapy was of statistical significance in univariate analysis the multivariable analysis excluded this as being independently important. Nevertheless, in this founder population of cases the generated model based on the variables studied correctly identified over $90 \%$ (formula summed outcome either 0 or 1 ). However, we felt that the predictabilty of the models would be best tested in a validating population. One of the more difficult surgical skills to acquire is the ability to judge if and when to operate on patients with SBO. It is generally recognized that clinically sick patients are more likely in need of an operation. In the case of CD causing obstruction this pattern may be obscured by the periodic behavior of $\mathrm{CD}$ as an inflammatory disease. Nevertheless we note that the presence of fever and a rapid pulse strongly supports the need for operation both in patients with or without a history of CD. In the case of CD a history of current smoking interestingly predicts the need for operation in this emergency setting. We are not aware of any other study linking a smoking history to the need for operation in such a precise manner, although a recent report does find an increased need for an operation in well defined smokers. ${ }^{37}$ In general smoking has a potential effect on immunity and on small bowel vasculature possibly increasing fibrostenosis. ${ }^{38}$ Several reports have extolled the predictive value of abdominal CT scan toward an operation. ${ }^{39,40}$ In our study, for cases of SBO without CD, most patients had reports of positive CT scans and as such were not helpful to predict the requirement for operation. By comparison, in patients with CD, the positive CT scan was quite a strong predictor as a need for operation. It is emphasized that other radiological modalities (such as barium small bowel follow through, MRI or CT enterography) were not evaluated because these tests were not employed in an emergency setting in our institution. However as outlined above these can be quite helpful. Because in our sample population several identified common clinical variables were strongly biased with the need for operation, these were omitted from further multivariate models. As such in the case of SBO without
$\mathrm{CD}$, the single variable of leukocytosis proved to be a fairly strong predictor of operative need. Although, this may be too vague by itself as only a minority had this as a positive variable, additional biased identifiers as described, strengthen the predictors.

Weaknesses in our study included a relatively small group of non CD, SB0 patients, which were chosen by the archives department. Although these patients were not matched to the CD group, biases may have been introduced by this method. Secondly, as previously stated, some of the more classical markers of inflammation (useful in CD), for example Creactive protein and sedimentation rate, were omitted due to the lack of sufficient available numbers. Whether these could have added any further information would have been of interest, but will need possible future assessment. Another feature of our study is the failure to define the duration of smoking history which may have an impact and also the lack of data on specific drug use, especially immunomodulators which may alter the course of CD. ${ }^{19}$ However, we were interested in simplicity and used variables in a dichotomous manner. Finally, the most important deficiency is the lack of a validating group, to determine whether our results are applicable to more general populations of SBO with CD. We felt that the complexity of the current evaluation would require a separate study applying current multivariable formulae.

\section{Conclusions}

In conclusion, this study allows quantitative values to be attached to clinical judgment in the decision making process regarding operative intervention in patients with SBO with or without $\mathrm{CD}$. This pattern may be applicable to naïve patients where the diagnosis of $\mathrm{CD}$ has not yet been established. We also note that input variables for therapeutic decisions may be different in SBO with CD or without CD. Finally, we feel that markers evaluated in our study do not adequately allow preoperative prediction of the cause of SBO with CD, although a previous operation makes adhesions a likely candidate for cause. Future studies should further evaluate other clinical and laboratory variables and the specific predictive role of radiological parameters (CT, US, etc) in such cases.

\section{References}

1. Miller G, Bowman J, Shrier I, Gordon PH. Etiology of small bowel obstruction. Am J Surg 2000;180:33-6.

2. Miller G, Bowman J, Shrier I, Gordon PH.
Natural history of patients with adhesive small bowel obstruction. Brit J Surg 2000;87:1240-7.

3. Harvey R, Bradshaw JM. A simple index of Crohn's disease activity. Lancet 1980;1: 1134-5.

4. Maconi G, Carsana L, Fociani P, et al. Small bowel stenosis in Crohn's disease: clinical, biochemical and ultrasonographic evaluation of histological features. Aliment Pharmacol Ther 2003;18:749-56.

5. Jancelewicz T, Vu LT, Shawo AE, et al. Predicting strangulated small bowel: an old problem revisited. J Gastrointest Surg 2009;13:93-9.

6. Aldemir M, Yagnur Y, Tacyildir. The predictive factors for necessity of operative treatment in adhesive small bowel obstruction cases. Acta Chi Belg 2004;104:76-80.

7. Yamamoto T, Umegae S, Kitagawa T, Matsumoto $K$. The value of plasma cytokine measurements for eth detection of strangulation in patients with bowel obstruction: a prospective, pilot study. Dis Colon Rectum 2005;48:1451-9.

8. Maglinte DDT, Howard TJ, Lillemoe KD, et al. Small-bowel obstruction: state-of-theart imaging and its role in clinical management. Clin Gastroenterol Hepatol 2008; 6:130-9.

9. Silen W, Hein MF, Goldman L. Strangulation obstruction of the small intestine. Arch Surg1962;85:121-9.

10. Sarr MG, Bulkley GB, Zuidema GD. Preoperative recognition of intestinal strangulation obstruction.Prognostic evaluation of diagnostic capability. Am J Surg 1983;145:176-82.

11. Maglinte DDT, Gage SN, Harmon BH, et al. Obstruction of the small intestine: Accuracy and role of CT in diagnosis. Radiology 1993;188:61-4.

12. O'Daly BJ, Ridgway PF, Keenan N, et al. Detected peritoneal fluid in small bowel obstruction is associated with need for surgical intervention. Can J Surg 2009; 52:201-6.

13. Yaffe BH, Korelitz BI. Prognosis for nonoperative management of small-bowel obstruction in Crohn's disease. J Clin Gastroenterol 1983;5:211-5.

14. Speranza V, Simi M, Leardi S, Prantera C. Indications, strategy and results of surgical management in 141 cases of Crohn's disease. Ital J Surg Sci 1983;13:5-12.

15. Bernstein CN, Loftus EV Jr, Ng SC, et al. Hospitalizations and surgery in Crohn's disease. Gut 2012;61:622-9.

16. Lennard-Jones JE. Classification of inflammatory bowel disease. Scand J Gastroenterol 1989;170:2-6.

17. Alvarez-Lobos M, Arostegui JI, Sans M, et al. Crohn's disease patients carrying Nod2/CARD15 gene variants have an 
increased and early need for first surgery due to stricturing disease and higher rate of surgical recurrence. Ann Surgery 2005; 242:693-700.

18. Reese GE, Nanidis T, Borysiewicz C, et al. The effect of smoking after surgery for Crohn's disease: a meta- analysis of observational studies. Int $\mathbf{J}$ Colorectal Dis 2008;23:1213-21.

19. Lakatos PL, Czegledi Z, Szamos T, et al. Perineal disease, small bowel disease, smoking, prior steroid or early azathioprine/biological therapy are predictors of disease behavior change in patients with Crohn's disease. World J Gastroenterol 2009;15:3504-10.

20. Louis E, Belaiche J, Reenaers C. Do clinical factors help to predict disease course in inflammatory bowel disease ? World $\mathrm{J}$ Gastroenterol 2010;16:2600-3.

21. Ramadas AV, Gunesh S, Thomas GAO, et al. Natural history of Crohn's disease in a population-based cohort from Cardiff (1986-2003): a study of changes in medical treatment and surgical resection rates. Gut 2010;59:1200-6.

22. Peyrin-Biroulet L, Oussalah A, Willet N, et al. Impact of azathioprine and tumour necrosis factorantagonists on the need for surgery in newly diagnosed Crohn's disease. Gut 2011;60:930-6.

23. Bernell 0, Lapidus A, Hellers G. Risk factors for surgery and postoperative recurrence in Crohn's disease. Ann Surg 2000;231:3845.

24. Bernell 0, Lapidus A, Hellers G. Riskfactors for surgery and recurrence in
907 patients with primary ileocecal Crohn's disease. Br J Surgery 2000;87: 1697-701.

25. Ukart JT, Anderson L, Li E, et al. Risk factors for surgical recurrence after ileocolic resection of Crohn's disease. Dis Colon Rectum 2008;51:1211-6.

26. Simillis C, Yamamoto T, Reese GE, et al. A meta-analysis comparing incidence of recurrence and indicatio for reoperation after surgeryu for perforating versus nonperforating Crohn's disease. Am J Gastroenterol 2008;103:196-205.

27. Zissin R, Hertz M, Paran H, et al. Small bowel obstruction secondary to Crohn's disease: CT findings. Abdom Imaging 2004;29:320-5.

28. Negaard A, Paulsen V, Berstad AE, et al. A prospective randomized comparison between two MRI studies of the small bowel in Crohn's disease, the oral contrast method and MR enteroclysis. Eur Radiol 2007;17:2294-301.

29. Jacene HA, Ginsburg $P$, Kwon J, et al. Prediction of the need for surgical intervention in obstructive Crohn's disease by18 F-FDG PET/CT. J Nucl Med 2009;50: 1751-9.

30. Zalcman M, Sy M, Donckier V, et al. Helical CT signs in the diagnosis of intestinal ischemia in small-bowel obstruction. Am J Radiol 2000;175:1601-7.

31. Zielinski MD, Eiken PW, Bannon MP, et al. Small bowel obstruction-who needs an operation? A multivariate prediction model. World J Surg 2010;34:910-9.

32. Magro F, Portela F, Lago P, et al. Crohn's disease in a southern European country: Montreal classification and clinical activity. Inflamm Bowel Dis 2009;15: 1343-50.

33. Cottone M, Rosselli M, Orlando A, et al. Smoking habits and recurrence in Cohn's disease. Gastroenterology 1994;106:643-8.

34. Cosnes J, Carbonnel F, Carrat F, et al. Effects of current and former cigarette smoking on the clinical course of Crohn's disease. Aliment Pharmacol Ther 1999;13: 1403-11.

35. Seksik P, Nion-Larmurier I, Sokol H, et al. Effects of light smoking consumption on the clinical course of Crohn's disease. Inflamm Bowel Dis 2009;15:734-41.

36. Kapsoritakis AN, Koukourakis MI, Sfiridaki A, et al. Mean platelet volume: A useful marker of inflammatory bowel disease activity. Am J Gastroenterol 2001;96: 776-81.

37. Johnson GJ, Cosnes J, Mansfield JC. Review article: smoking cessation as primary therapy to modify the course of Crohn's disease. Aliment Pharmacol Ther 2005;21:921-31.

38. Mayo-Smith WW, Wittenberg J, Bennet GL, et al. The CT small bowel faeces sign: description and clinical significance. Clin Radiol 1995;50:765-7.

39. Bogusevicius A, Pundzius J, Maleckas A, Vilkauskas L. Computer-aided diagnosis of the character of bowel obstruction. Int Surg 1999;84:225-8

40. Segatto E, Mortele KJ, Ji H, et al. Acute small bowel ischemia: CT imaging findings. Semin Ultrasound CT MRI 2003; 24:364-76. 